Thiago Antônio de Mello ${ }^{1}$

Anadergh Barbosa-Branco ${ }^{1}$

\section{Prevalência de benefícios auxílio-doença entre trabalhadores da Construção no Brasil em 2009}

\author{
Prevalence of sickness benefits among construction workers in \\ Brazil in 2009
}

${ }^{1}$ Universidade de Brasília, Programa de Pós-Graduação em Saúde Coletiva. Brasília, DF, Brasil.

Contato

Thiago Antônio de Mello

E-mail:

thiagomello@unb.br

Este artigo é parte da dissertação de mestrado de Thiago Antônio de Mello, intitulada "Incapacidade para o trabalho no ramo da Construção no Brasil", defendida em 2013 junto ao Programa de Pós-Graduação em Saúde Coletiva do Departamento de Saúde Coletiva da Faculdade de Ciências da Saúde da Universidade de Brasília.

O presente trabalho não contou com financiamento externo, não é baseado em tese e não foi apresentado em reunião científica.

Os autores declaram que não há conflito de interesse profissional, financeiro ou benefícios diretos e indiretos que possam influenciar os resultados desta pesquisa.
Recebido: 09/09/2013

Revisado: 02/07/2014

Aprovado: 07/07/2014

\section{Resumo}

Objetivo: estimar a prevalência de Benefícios Auxílio-Doença (BAD) entre trabalhadores do ramo da Construção e a potencial influência do sexo, idade e ramo de atividade no quadro de incapacidade para o trabalho, no Brasil, em 2009. Método: estudo transversal de base populacional baseado nos BAD concedidos pela Previdência Social. Do Sistema Único de Benefícios e do Cadastro Nacional de Informações Sociais extraíram-se informações sobre ramo de atividade, sexo, idade, causa clínica e espécie de benefício. A população de estudo correspondeu à média mensal dos vínculos empregatícios declarados em 2009 (1.784.772). Resultados: foram concedidos 81.235 BAD, resultando em prevalência de 455,2/10.000 vínculos, com predomínio da espécie BAD previdenciária (Razão de Prevalência [RP] 3,1), do sexo masculino (RP 1,3) e dos ramos de atividade Obras de acabamento, Construção de obras de arte e Obras de terraplenagem. Homens caracterizaram 76,7\% mais BAD acidentários que mulheres. As principais causas diagnósticas foram Lesões, Doenças osteomusculares e Doenças digestivas. As categorias clínicas mais prevalentes foram Dorsalgia, Fratura ao nível do punho e da mão, Fratura da perna e Hérnia inguinal. A prevalência aumentou com a idade. Conclusão: a prevalência mostrou-se influenciada pela espécie de benefício, ramo de atividade, sexo e idade. Os resultados sugerem potenciais mecanismos de subnotificação/demanda previdenciária.

Palavras-chave: incapacidade para o trabalho; auxílio-doença; construção; atividade econômica; saúde do trabalhador.

\begin{abstract}
Objective: to estimate the prevalence of sickness benefits among workers in the construction industry and the potential influence of sex, age and branch of activity within the framework of incapacity for work in Brazil in 2009. Methods: a cross-sectional population study based on sickness benefits provided by the Brazilian Social Security. Information about the branch of activity, sex, age, cause and type of clinical benefit of workers was extracted from the Unified Benefits and the National Registry of Social Information. The study population corresponded to the average monthly employment relations declared in 2009 (1,784,772). Results: the study population was granted 81,235 sickness benefits, resulting in a prevalence of 455.2/10,000 bonds, predominantly non-work related benefits (Prevalence Ratio [PR] 3,1), male (PR 1,3), and branches of activity: Finishing works, Construction works of art and Earthwork. Men were granted 76.7\% more sickness benefits related to work than women. The main causes were Injuries, Musculoskeletal Diseases, and Digestive Diseases. The most prevalent clinical categories were Back pain, Fracture at the wrist and hand, Fracture of the leg and Inguinal hernia. Prevalence increased with age. Conclusion: the prevalence of sickness benefits was influenced by the type of benefit, type of activity, age and sex. The results of this study suggest potential mechanisms of underreporting/social security demand.
\end{abstract}

Keywords: work disability; sickness benefit; construction; economic activity; occupational health. 


\section{Introdução}

O absenteísmo por doença e a consequente incapacidade para o trabalho são um problema de saúde pública em todo o mundo, com considerável custo socioeconômico (ROELEN et al., 2009). Estudos internacionais têm mostrado que fatores como ocupação, condições de trabalho e nível de escolaridade são fortes determinantes de incapacidade para o trabalho (PIHA et al., 2010; LAAKSONEN et al., 2010).

Estudo brasileiro recente, de base populacional, mostrou a importância do ramo de atividade econômica na incidência de incapacidade para o trabalho em 2008 (BARBOSA-BRANCO; SOUZA; STEENSTRA, 2011). Esse estudo apontou o ramo Construção de edifícios como a terceira maior incidência bruta de incapacidade temporária para o trabalho em geral, a quarta quando analisados separadamente os benefícios auxílio-doença previdenciário (sem nexo técnico com o trabalho) e a terceira entre os acidentários (com nexo técnico com o trabalho) (BARBOSA-BRANCO; SOUZA; STEENSTRA, 2011). Em outro estudo desenvolvido com a mesma população e com métodos semelhantes, mas considerando apenas doenças osteomusculares, os resultados em termos de distribuição das taxas de prevalência desse grupo foram semelhantes aos do estudo anterior, a saber, a quarta maior taxa de prevalência, no conjunto dos benefícios auxílio-doença, e a segunda quando considerados apenas os benefícios relacionados ao trabalho (VIEIRA; ALBUQUERQUEOLIVEIRA; BARBOSA-BRANCO, 2011).

Achados em um estudo de base populacional sobre benefícios auxílio-doença devido a transtornos mentais no Brasil mostraram que, do total desses benefícios concedidos aos trabalhadores do ramo Construção, mais de $40 \%$ foram decorrentes de Transtornos mentais e comportamentais devidos ao uso de substância psicoativa. O ramo Construção de edifícios apresentou a maior duração mediana dos afastamentos por incapacidade para o trabalho decorrentes de transtornos mentais, o que indica, potencialmente, maior gravidade e cronicidade dos casos (BARBOSABRANCO; BÜLTMANN; STEENSTRA, 2012).

A alta rotatividade, a subnotificação dos registros de acidentes e doenças do trabalho e as elevadas taxas de informalidade nos ramos da Construção, em particular na Construção de edifícios, contribuem para a escassez de pesquisas epidemiológicas sobre incapacidade para o trabalho nesse setor produtivo (SANTANA; OLIVEIRA, 2004).

O perfil do trabalhador na construção, mesmo o empregado, é de indivíduos jovens, do sexo masculino, com baixa escolaridade, reduzida qualificação profissional, além de notável contingente de migrantes (DEPARTAMENTO INTERSINDICAL DE ESTATÍSTICA
E ESTUDOS SOCIOECONÔMICOS, 2001; RINGEN; SEEGAL; WEEKS, 1998).

Empiricamente, sabe-se que os trabalhadores informais contam com menor assistência em relação à saúde do que aqueles minimamente amparados pela legislação trabalhista. Considerando-se as altas taxas de informalidade observadas no ramo da Construção (SANTANA; OLIVEIRA, 2004), é possível que esse grupo de trabalhadores apresente quadros de adoecimento mais severos do que os encontrados em trabalhadores empregados (BARBOSA-BRANCO; SOUZA; STEENSTRA, 2011).

A ocorrência de problemas de saúde na construção civil está potencialmente associada ao grande número de riscos ocupacionais, como o trabalho em grandes alturas, o manejo de máquinas, equipamentos e ferramentas perfurocortantes, instalações elétricas, uso de veículos automotores, posturas e movimentos antiergonômicos, como na elevação de objetos pesados, além de estresse devido à transitoriedade e à alta rotatividade (SOROCK; SMITH; GOLDOFT, 1993; LIPSCOMB; DEMENT; RODRIGUEZ-ACOSTA, 2000; JEONG, 1998; CATTLEDGE; HENDRICKS; STANEVICH, 1996).

Estudos internacionais mostram que nesse ramo de atividade, dentre as enfermidades mais incapacitantes para o trabalho, destacam-se as doenças musculoesqueléticas, dermatites, intoxicação por chumbo e asbestose (BURKHART et al., 1993) e que trabalhadores apresentam alta prevalência de abuso de álcool (HOFFMANN; BRITTINGHAM; LARISON, 1996), inclusive durante o horário de trabalho, contribuindo sobremaneira para o agravamento dos riscos já existentes nos ambientes laborais.

Os trabalhadores desse ramo de atividade no Brasil apresentam os menores níveis salariais dentre os ramos da indústria, o que lhes impõe, com frequência, a necessidade de estender a jornada de trabalho por meio da realização de horas extras ou da adoção de regime de tarefas e, como consequência, tem-se uma maior exposição aos riscos de acidentes e doenças do trabalho (SERVIÇO SOCIAL DA INDÚSTRIA, 1998).

A atividade da construção civil é considerada uma das mais perigosas em todo o mundo, liderando as taxas de acidentes de trabalho fatais, não fatais e de anos de vida perdidos (RINGEN; SEEGAL; WEEKS, 1998). Os acidentes de trabalho são a principal causa ocupacional de morte na construção civil (SOROCK; SMITH; GOLDOFT, 1993; BURKHART et al., 1993).

Apesar dos dados disponíveis na literatura serem principalmente referentes à Construção de edifícios (Classificação Nacional de Atividades Econômicas [CNAE]-Divisão 41), o ramo da Construção (CNAESeção F) é ainda composto pelos ramos Obras de 
infraestrutura (CNAE-Divisão 42) e Serviços especializados para construção (CNAE-Divisão 43). As atividades típicas realizadas, bem como os riscos ocupacionais presentes nesses três ramos da Construção, diferem sobremaneira entre si, o que nos leva a inferir que o perfil epidemiológico de adoecimento desses trabalhadores seja diferente. Dessa forma, torna-se importante avaliar essas potenciais diferenças visando melhor compreender esses processos de adoecimento, $\mathrm{e}$ dessa forma contribuir no estabelecimento de medidas preventivas mais eficazes.

Frente a esse contexto, objetiva-se estimar a prevalência de benefícios auxílio-doença concedidos aos trabalhadores empregados no ramo da Construção e a potencial influência do sexo, da idade, da espécie de benefício e do ramo de atividade específico (CNAEclasse) no quadro de incapacidade para o trabalho no Brasil, em 2009.

\section{Métodos}

Trata-se de estudo descritivo, com base na análise dos Benefícios Auxílio-Doença (BAD) concedidos pelo Instituto Nacional de Seguro Social - INSS aos trabalhadores empregados no ramo da Construção (CNAE 2.0, Seção F) no Brasil, em 2009. A incapacidade para o trabalho foi avaliada pela prevalência de BAD. Para concessão de um BAD a perícia do INSS avalia a presença ou não da incapacidade para o trabalho e não apenas a presença de um agravo. Portanto, neste estudo, BAD e incapacidade para o trabalho são utilizados como termos equivalentes. Detalhes do esquema de concessão de auxílio-doença no Brasil, bem como o detalhamento das fontes de dados utilizadas neste estudo e da forma de tratamento dos dados foram descritos em estudos anteriores (BARBOSA-BRANCO; SOUZA; STEENSTRA, 2011; BARBOSA-BRANCO; BÜLTMANN; STEENSTRA, 2012).

Os dados analisados neste estudo são oriundos de duas grandes bases de dados sob a responsabilidade do INSS: a) Sistema Único de Benefícios - SUB, que concentra o registro de todos os benefícios concedidos aos segurados da iniciativa privada no Brasil, e incluem os BAD, objeto desta investigação; b) Cadastro Nacional de Informações Sociais - CNIS, o qual recebe, por determinação legal, informações mensais dos vínculos empregatícios mantidos pelas empresas. Para o tratamento dos dados utilizou-se o sistema de armazenamento e gerenciamento de bancos de dados Microsoft Office Access ${ }^{\circledR}$. Do SUB foram extraídas informações sobre o ramo de atividade econômica patronal, sexo, idade, causa clínica (CID-10) e espécie de benefício (previdenciário, acidentário). Essa base constitui o numerador. Do CNIS foram coletados dados sobre o ramo de atividade econômica patronal (CNAE
Seção, Divisão e Classe), sexo e idade do trabalhador. Os dados dessa base foram usados como denominador para os cálculos da prevalência, que foram realizados por meio do programa de planilha eletrônica Microsoft Office Excel ${ }^{\circledR}$. As taxas de incapacidade apresentadas referem-se às prevalências e razões de prevalências (RP) obtidas para as variáveis de interesse.

A população de estudo corresponde à média dos vínculos empregatícios declarados pelos empregadores na CNAE-Seção F (Construção) no Brasil, em 2009 (1.784.772), o qual corresponde a $5,4 \%$ dos vínculos empregatícios declarados no Brasil em 2009. Foi considerado caso todo benefício auxílio-doença concedido à população de estudo no período de $1 / 1$ a 31/12/2009.

Para a análise individualizada da prevalência dos agrupamentos CID-10 foi adotado o critério de corte de 2.000 casos por agrupamento, a fim de evitar distorções numéricas. Em relação ao ramo de atividade, não foram individualmente consideradas, para análise, as CNAE com menos de 1.000 benefícios concedidos no período. Foram considerados para análise individualizada os resultados para as categorias diagnósticas que apresentaram mais de $1.000 \mathrm{BAD}$ em 2009, representadas em 12 categorias (40,3\% da casuística).

A fim de simplificar a leitura e compreensão dos resultados desta pesquisa, os nomes dos grupos diagnósticos (capítulos CID-10) foram simplificados na forma a seguir, sem prejuízo quanto aos agrupamentos e categorias neles contidos: I - Doenças infecciosas; II - Neoplasias; III - Doenças do sangue; IV - Doenças endócrinas; V - Doenças mentais; VI - Doenças do sistema nervoso; VII - Doenças do olho; VIII - Doenças do ouvido; IX - Doenças do aparelho circulatório; X - Doenças respiratórias; XI - Doenças digestivas; XII - Doenças da pele; XIII - Doenças osteomusculares; XIV - Doenças geniturinárias; XIX - Lesões; e XXI - Fatores que influenciam o estado de saúde.

Com o mesmo objetivo, os seguintes ramos de atividades também tiveram sua nomenclatura CNAE-classe simplificada, sem que se alterasse para análise o rol de atividades constantes na relação original: 4211 - Construção de rodovias; 4212 - Construção de obras de arte; 4221 - Obras para energia elétrica e telecomunicações; 4222 - Construção de redes de água e esgoto; 4292 - Montagem de instalações industriais; 4322 - Instalações hidráulicas; e 4329 - Obras de instalações em construções.

Com relação aos aspectos éticos, esclarecemos que foram utilizados exclusivamente dados secundários oriundos de grandes bases públicas de dados, sem que houvesse meios para a identificação dos sujeitos individualmente. 


\section{Resultados}

Em 2009 foram concedidos 81.235 BAD aos trabalhadores empregados na Construção, resultando em uma prevalência de 455,2 casos para cada 10.000 vínculos empregatícios (Tabela 1). Quanto à espécie de benefício predominaram os BAD previdenciários em uma razão de 3,1 em relação aos BAD acidentários (Tabela 1).

Em relação aos grupos diagnósticos (capítulos CID-10) que deram origem aos benefícios, predominaram as Lesões (180,1); Doenças osteomusculares $(90,1)$; e as Doenças digestivas $(39,4)$, independente da espécie de benefício (Tabela 1). O grupo das Lesões representou $39,6 \%$ dos $\mathrm{BAD}$ e esses três grupos juntos responderam por $68,0 \%$ dos BAD.

A análise da potencial influência do sexo na prevalência de BAD mostrou que os homens, no geral $(476,3)$, apresentaram prevalência 30,0\% maior do que as mulheres $(374,5)$ e $76,7 \%$ maior nexo técnico (relação com o trabalho) (Tabela 1). A maior diferença entre os sexos em relação à prevalência de $\mathrm{BAD}$ segundo os grupos diagnósticos foi observada em relação às Lesões (RP 2,7), Doenças infecciosas (RP 2,2) e Doenças do olho (RP 2,2) (Tabela 1).

Entre os homens, as Lesões tiveram maior peso no quadro da incapacidade, representando 41,1\% do total de BAD e $64,8 \%$ daqueles relacionados ao trabalho, enquanto que entre as mulheres essa representatividade foi de 19,1\% no geral e 42,3\% entre os BAD acidentários.

Dentre os grupos mais prevalentes, as Doenças osteomusculares e as Doenças mentais foram mais impactantes entre as mulheres, representando juntas $34,4 \%$ do total de BAD nesse sexo, contrapondo-se a $26,3 \%$ entre os homens. Esse impacto fica ainda mais

Tabela 1 Prevalência de benefícios auxílio-doença no ramo da Construção (por 10 mil vínculos)* segundo sexo, espécie de benefício e grupo CID-10 - Brasil - 2009

\begin{tabular}{|c|c|c|c|c|c|c|c|c|c|c|c|c|c|}
\hline \multirow{3}{*}{$\begin{array}{c}\text { Cap. } \\
\text { CID-10 }\end{array}$} & \multicolumn{6}{|c|}{ Sexo } & & & & \multicolumn{4}{|c|}{ Razão de prevalência } \\
\hline & \multicolumn{3}{|c|}{ Masculino } & \multicolumn{3}{|c|}{ Feminino } & \multicolumn{3}{|c|}{ Total } & \multirow{2}{*}{$\begin{array}{l}M / F \\
B 31\end{array}$} & \multirow{2}{*}{$\begin{array}{l}M / F \\
B 91\end{array}$} & \multirow{2}{*}{$\begin{array}{c}M / F \\
B 31+ \\
B 91 \\
\end{array}$} & \multirow{2}{*}{$\begin{array}{c}M+F \\
B 31 / \\
B 91\end{array}$} \\
\hline & B31 & $B 91$ & $\begin{array}{c}B 31+ \\
B 91 \\
\end{array}$ & $B 31$ & $B 91$ & $\begin{array}{c}B 31+ \\
\text { B91 } \\
\end{array}$ & $B 31$ & B91 & $\begin{array}{c}B 31+ \\
B 91 \\
\end{array}$ & & & & \\
\hline XIX & 117,6 & 78,0 & 195,6 & 46,2 & 25,2 & 71,4 & 108,5 & 71,6 & 180,1 & 2,5 & 3,1 & 2,7 & 1,5 \\
\hline XIII & 63,4 & 29,8 & 93,2 & 59,7 & 25,8 & 85,5 & 61,4 & 28,6 & 90,1 & 1,1 & 1,2 & 1,1 & 2,1 \\
\hline$X I$ & 37,1 & 5,0 & 42,1 & 23,2 & 0,4 & 23,6 & 34,9 & 4,5 & 39,4 & 1,6 & 12,3 & 1,8 & 7,8 \\
\hline IX & 32,6 & 1,5 & 34,1 & 25,4 & 0,9 & 26,4 & 31,1 & 1,4 & 32,5 & 1,3 & 1,6 & 1,3 & 22,3 \\
\hline V & 31,0 & 1,2 & 32,2 & 41,9 & 1,3 & 43,3 & 31,1 & 1,2 & 32,2 & 0,7 & 0,9 & 0,7 & 26,1 \\
\hline I & 11,7 & 0,7 & 12,4 & 5,1 & 0,5 & 5,6 & 10,8 & 0,7 & 11,5 & 2,3 & 1,6 & 2,2 & 15,6 \\
\hline II & 9,9 & 0,2 & 10,0 & 29,7 & 0,1 & 29,7 & 11,3 & 0,2 & 11,4 & 0,3 & 2,8 & 0,3 & 64,8 \\
\hline XIV & 7,4 & 0,1 & 7,5 & 18,1 & 0,1 & 18,2 & 8,1 & 0,1 & 8,2 & 0,4 & 0,7 & 0,4 & 85,0 \\
\hline VII & 7,9 & 0,8 & 8,7 & 3,8 & 0,1 & 3,9 & 7,3 & 0,7 & 8,1 & 2,1 & 6,1 & 2,2 & 9,8 \\
\hline $\mathrm{VI}$ & 6,9 & 0,8 & 7,7 & 9,4 & 3,4 & 12,8 & 6,9 & 1,0 & 7,9 & 0,7 & 0,2 & 0,6 & 6,8 \\
\hline$x$ & 5,6 & 0,6 & 6,2 & 5,6 & 0,7 & 6,4 & 5,5 & 0,6 & 6,1 & 1,0 & 0,8 & 1,0 & 9,2 \\
\hline XII & 5,1 & 0,7 & 5,9 & 3,9 & 0,4 & 4,3 & 4,9 & 0,7 & 5,6 & 1,3 & 1,8 & 1,4 & 7,1 \\
\hline XXI & 3,6 & 0,4 & 4,0 & 4,4 & 0,2 & 4,6 & 3,5 & 0,4 & 3,9 & 0,8 & 2,0 & 0,9 & 9,3 \\
\hline IV & 2,7 & 0,2 & 2,9 & 2,5 & - & 2,5 & 2,7 & 0,1 & 2,8 & 1,1 & - & 1,1 & 19,7 \\
\hline VIII & 1,5 & 0,1 & 1,7 & 1,7 & 0,1 & 1,7 & 1,5 & 0,1 & 1,6 & 0,9 & 2,1 & 1,0 & 11,7 \\
\hline III & 0,7 & 0,0 & 0,7 & 1,1 & - & 1,1 & 0,7 & 0,0 & 0,7 & 0,7 & - & 0,7 & 25,6 \\
\hline Outros & 11,2 & 0,1 & 11,4 & 33,1 & 0,3 & 33,5 & 12,8 & 0,2 & 12,9 & 0,3 & 0,4 & 0,3 & 84,4 \\
\hline Total & 355,9 & 120,3 & 476,3 & 314,9 & 59,6 & 374,5 & 343,1 & 112,1 & 455,2 & 1,1 & 2,0 & 1,3 & 3,1 \\
\hline
\end{tabular}

* A população de estudo corresponde à média dos vínculos empregatícios declarados pelos empregadores na CNAE-Seção F-Construção no período: 1.784.772 vínculos

B31: Auxílio-doença previdenciário; B91: Auxílio-doença acidentário; M: Masculino; F: Feminino; Capítulos (grupos) CID-10 - Descrição: I - Algumas doenças infecciosas e parasitárias; II - Neoplasias (tumores); III - Doenças do sangue e dos órgãos hematopoéticos e alguns transtornos imunitários; IV - Doenças endócrinas, nutricionais e metabólicas; V - Transtornos mentais e comportamentais; VI - Doenças do sistema nervoso; VII - Doenças do olho e anexos; VIII - Doenças do ouvido e da apófise mastóide; IX - Doenças do aparelho circulatório; X-Doenças do aparelho respiratório; XI - Doenças do aparelho digestivo; XII - Doenças da pele e do tecido subcutâneo; XIII - Doenças do sistema osteomuscular e do tecido conjuntivo; XIV - Doenças do aparelho geniturinário; XIX - Lesões, envenenamento e algumas outras consequências de causas externas; XXI - Fatores que influenciam o estado de saúde e o contato com os serviços de saúde 
claro quando considerado apenas os BAD acidentários (45,5\% no feminino comparado a 25,8\% no masculino).

Na análise da espécie de benefício (previdenciário e acidentário) em relação aos grupos diagnósticos, observa-se que, enquanto os BAD previdenciários seguiram a mesma tendência geral independente do sexo, os acidentários apresentaram elevadas razões de prevalência entre os sexos, principalmente para os grupos Doenças digestivas (RP 12,3), Doenças do olho (RP 6,1) e Lesões (RP 3,1) (Tabela 1).

Ao analisar a potencial influência do ramo de atividade na prevalência de BAD segundo os grupos diagnósticos (Tabela 2) observaram-se variações importantes. Os ramos Obras de acabamento, Construção de obras de arte e Obras de terraplenagem apresentaram as maiores prevalências de BAD em geral e lideraram essa taxa em relação à maioria dos grupos diagnósticos. Em todos os ramos de atividades analisados, os três maiores grupos de causa diagnóstica para os afastamentos foram as Lesões, as Doenças osteomusculares e as Doenças digestivas, exceto nos ramos Obras para energia elétrica e telecomunicações, e Instalações elétricas. Nesses ramos, o terceiro maior grupo foi o das Doenças mentais.

Os ramos de atividade apresentaram taxas de incapacidade heterogêneas tanto no geral quanto em relação aos grupos diagnósticos específicos. O ramo com maior prevalência de Lesões, Obras de acabamento, apresentou taxas de afastamentos 58,4\% maior que a totalidade dos ramos e $81,8 \%$ maior que o ramo com menor prevalência. Chamou atenção a alta prevalência de benefícios decorrentes de Doenças da pele entre os trabalhadores de Obras de terraplenagem (Tabela 2). Nesse ramo, esse grupo de doenças que representou

Tabela 2 Prevalência de benefícios auxílio-doença no ramo da Construção (por 10 mil vínculos)* segundo ramo de atividade econômica e grupo CID-10 - Brasil - 2009

\begin{tabular}{|c|c|c|c|c|c|c|c|c|c|c|c|c|c|c|}
\hline $\begin{array}{c}\text { Cap. } \\
\text { CID-10 }\end{array}$ & 4120 & 4211 & 4212 & 4221 & 4222 & 4292 & $\begin{array}{l}\text { CNAE } \\
4312 \\
\end{array}$ & 4313 & 4321 & 4322 & 4329 & 4330 & Outros & Total \\
\hline XIX & 169,9 & 156,9 & 196,7 & 176,1 & 166,7 & 199,8 & 255,9 & 218,9 & 222,6 & 177,0 & 218,9 & 285,3 & 186,3 & 180,1 \\
\hline XIII & 84,6 & 75,9 & 134,2 & 99,0 & 82,7 & 112,1 & 91,9 & 116,5 & 99,9 & 75,9 & 111,0 & 132,5 & 72,6 & 90,1 \\
\hline XI & 37,8 & 36,7 & 62,2 & 37,2 & 37,1 & 46,5 & 41,3 & 48,6 & 34,8 & 30,5 & 49,8 & 54,2 & 34,9 & 39,4 \\
\hline IX & 31,9 & 32,7 & 42,6 & 21,1 & 31,8 & 35,3 & 40,1 & 46,6 & 32,2 & 28,5 & 37,4 & 46,1 & 32,7 & 32,5 \\
\hline V & 29,9 & 28,7 & 42,6 & 41,8 & 25,9 & 39,9 & 33,5 & 39,1 & 35,0 & 28,3 & 41,1 & 51,4 & 24,3 & 32,2 \\
\hline I & 11,7 & 9,4 & 17,1 & 7,7 & 11,8 & 11,6 & 10,1 & 12,5 & 10,9 & 7,7 & 15,8 & 19,6 & 8,0 & 11,5 \\
\hline II & 11,4 & 10,7 & 12,9 & 9,3 & 9,9 & 11,1 & 9,0 & 16,9 & 12,4 & 12,8 & 13,7 & 15,4 & 12,7 & 11,4 \\
\hline XIV & 8,3 & 8,3 & 12,0 & 7,9 & 6,9 & 8,3 & 10,1 & 11,7 & 6,8 & 3,7 & 8,6 & 11,5 & 6,5 & 8,2 \\
\hline VII & 7,9 & 6,7 & 14,7 & 7,1 & 8,3 & 8,2 & 7,4 & 8,9 & 7,2 & 4,9 & 9,4 & 9,8 & 11,6 & 8,1 \\
\hline VI & 7,5 & 7,8 & 12,0 & 7,7 & 7,3 & 9,0 & 10,5 & 8,3 & 7,5 & 6,3 & 10,4 & 9,8 & 5,8 & 7,9 \\
\hline$x$ & 5,9 & 5,0 & 9,0 & 6,0 & 6,6 & 6,9 & 6,6 & 5,0 & 4,9 & 4,3 & 7,9 & 8,0 & 5,1 & 6,1 \\
\hline XII & 5,8 & 3,9 & 9,3 & 3,6 & 5,2 & 6,2 & 6,2 & 10,0 & 5,0 & 3,7 & 6,5 & 8,7 & 5,1 & 5,6 \\
\hline$X X I$ & 3,8 & 3,2 & 4,8 & 3,6 & 3,4 & 4,4 & 4,7 & 5,0 & 4,6 & 5,7 & 4,7 & 5,2 & 3,6 & 3,9 \\
\hline IV & 2,8 & 2,5 & 2,4 & 3,2 & 2,5 & 3,3 & 3,9 & 5,3 & 2,0 & 3,1 & 2,9 & 0,7 & 1,5 & 2,8 \\
\hline VIII & 1,5 & 1,5 & 2,4 & 2,5 & 1,4 & 2,7 & 0,4 & 3,1 & 1,5 & 2,6 & 1,6 & 1,0 & 0,7 & 1,6 \\
\hline III & 0,7 & 0,9 & 0,3 & 0,6 & 0,8 & 1,0 & 1,2 & 0,8 & 0,5 & 0,6 & 0,9 & 2,1 & 1,1 & 0,7 \\
\hline Outros & 14,3 & 12,0 & 14,7 & 13,4 & 9,3 & 12,2 & 12,1 & 18,9 & 8,5 & 10,3 & 11,7 & 12,2 & 10,2 & 12,9 \\
\hline Total & 435,7 & 402,8 & 590,0 & 447,8 & 417,4 & 518,5 & 544,8 & 576,0 & 496,1 & 405,9 & 552,2 & 673,7 & 422,6 & 455,2 \\
\hline
\end{tabular}

*A população de estudo corresponde à média dos vínculos empregatícios declarados pelos empregadores na CNAE-Seção F-Construção no período: 1.784.772 vínculos

Capítulos (grupos) CID-10 - Descrição: I - Algumas doenças infecciosas e parasitárias; II - Neoplasias (tumores); III - Doenças do sangue e dos órgãos hematopoéticos e alguns transtornos imunitários; IV - Doenças endócrinas, nutricionais e metabólicas; V - Transtornos mentais e comportamentais; VI - Doenças do sistema nervoso; VII - Doenças do olho e anexos; VIII - Doenças do ouvido e da apófise mastóide; IX - Doenças do aparelho circulatório; X - Doenças do aparelho respiratório; XI - Doenças do aparelho digestivo; XII - Doenças da pele e do tecido subcutâneo; XIII - Doenças do sistema osteomuscular e do tecido conjuntivo; XIV - Doenças do aparelho geniturinário; XIX - Lesões, envenenamento e algumas outras consequências de causas externas; XXI - Fatores que influenciam o estado de saúde e o contato com os serviços de saúde; Classes CNAE - Descrição: 4120 - Construção de edifícios; 4211 - Construção de rodovias e ferrovias; 4212 - Construção de obras de arte especiais; 4221 - Obras para geração e distribuição de energia elétrica e para telecomunicações; 4222 - Construção de redes de abastecimento de água, coleta de esgoto e construções correlatas; 4292 - Montagem de instalações industriais e de estruturas metálicas; 4312 - Perfurações e sondagens; 4313 - Obras de terraplanagem; 4321 - Instalações elétricas; 4322 - Instalações hidráulicas, de sistemas de ventilação e refrigeração; 4329 - Obras de instalações em construções não especificadas anteriormente; 4330 - Obras de acabamento 
a quarta causa clínica de incapacidade, em termos de correlação com o trabalho (RP 7,1) (Tabela 1), teve prevalência 78,6\% maior que a da população de estudo e $177,8 \%$ maior que a do ramo Obras para energia elétrica e telecomunicações (Tabela 2).

Essa mesma análise quando realizada segundo o agrupamento CID-10 mostrou que, dentre os 19 maiores agrupamentos, nove destes figuram no grupo das Lesões; três de Doenças osteomusculares e três de Doenças do aparelho circulatório (Tabela 3). O ramo Obras de acabamento apresentou taxas superiores às dos trabalhadores da Construção em geral em todos os agrupamentos, exceto para Doenças hipertensivas (Tabela 3). O ramo Construção de obras de arte apresentou prevalência de Dorsopatias 48,9\% maior do que a Construção em geral, enquanto o ramo Perfurações e sondagens apresentou 93,8\% maior prevalência para Traumatismos do punho e da mão do que o conjunto dos trabalhadores da Construção.

O ramo Construção de edifícios, CNAE divisão 41, apresentou o maior número de vínculos empregatícios dentre os ramos da Construção (dados não tabulados), e taxas de incapacidade para o trabalho, em geral, menores do que as dos demais CNAE (Tabelas 2 e 3).

Tabela 3 Prevalência de benefícios auxílio-doença no ramo da Construção (por 10 mil vínculos)* segundo ramo de atividade econômica e agrupamento CID-10 - Brasil - 2009

\begin{tabular}{|c|c|c|c|c|c|c|c|c|c|c|c|c|c|c|}
\hline \multirow{2}{*}{$\begin{array}{c}\text { Agrupamento } \\
\text { CID-10 }\end{array}$} & \multicolumn{13}{|c|}{ CNAE } & \multirow{2}{*}{ Total } \\
\hline & 4120 & 4211 & 4212 & 4221 & 4222 & 4292 & 4312 & 4313 & 4321 & 4322 & 4329 & 4330 & Outros & \\
\hline M40-M54 & 46,1 & 40,3 & 70,3 & 45,8 & 44,4 & 50,9 & 52,2 & 66,0 & 49,1 & 32,8 & 56,9 & 62,9 & 37,4 & 47,2 \\
\hline S60-S69 & 41,5 & 36,8 & 41,1 & 35,7 & 42,3 & 47,4 & 84,9 & 52,4 & 49,8 & 50,8 & 58,5 & 61,5 & 44,7 & 43,8 \\
\hline S80-S89 & 32,2 & 32,6 & 50,1 & 42,6 & 32,7 & 42,9 & 42,8 & 48,8 & 47,2 & 39,7 & 43,7 & 54,5 & 39,2 & 36,2 \\
\hline K40-K46 & 23,9 & 22,2 & 38,1 & 18,9 & 23,7 & 31,6 & 26,5 & 25,8 & 22,6 & 16,6 & 28,9 & 33,6 & 18,2 & 24,2 \\
\hline S90-\$99 & 22,8 & 21,5 & 23,1 & 24,5 & 23,1 & 26,4 & 30,4 & 30,2 & 27,0 & 22,6 & 28,8 & 44,0 & 22,5 & 24,1 \\
\hline M00-M25 & 19,9 & 19,8 & 34,2 & 26,8 & 20,4 & 37,3 & 23,4 & 29,1 & 26,2 & 26,8 & 28,5 & 32,9 & 12,0 & 22,6 \\
\hline M60-M79 & 16,7 & 14,2 & 25,8 & 24,7 & 16,5 & 19,9 & 14,4 & 18,6 & 22,1 & 13,7 & 22,2 & 32,2 & 22,1 & 18,1 \\
\hline S50-S59 & 16,6 & 16,1 & 17,7 & 15,8 & 14,4 & 16,9 & 24,9 & 18,0 & 22,9 & 14,3 & 21,0 & 31,8 & 15,2 & 17,1 \\
\hline S40-S49 & 15,9 & 14,9 & 18,9 & 17,2 & 14,6 & 21,8 & 17,5 & 20,3 & 19,7 & 15,7 & 20,8 & 24,5 & 19,2 & 16,8 \\
\hline F10-F19 & 13,3 & 11,4 & 16,2 & 13,8 & 11,2 & 20,1 & 15,6 & 20,3 & 14,5 & 13,7 & 16,5 & 25,5 & 9,4 & 13,8 \\
\hline S00-S09 & 8,6 & 7,5 & 12,3 & 8,3 & 9,4 & 10,2 & 14,4 & 13,6 & 9,1 & 6,9 & 12,7 & 15,7 & 9,8 & 9,3 \\
\hline 180-189 & 8,2 & 10,2 & 15,0 & 6,8 & 7,9 & 10,9 & 7,0 & 11,4 & 7,8 & 7,4 & 10,7 & 12,2 & 8,0 & 8,7 \\
\hline F30-F39 & 8,0 & 7,4 & 14,1 & 15,2 & 6,2 & 7,0 & 8,6 & 9,7 & 10,3 & 6,9 & 11,7 & 11,9 & 6,5 & 8,7 \\
\hline $\mathrm{C} 00-\mathrm{C} 97$ & 7,6 & 7,1 & 8,4 & 5,3 & 7,3 & 6,7 & 6,6 & 13,0 & 7,8 & 9,7 & 8,5 & 9,8 & 7,6 & 7,6 \\
\hline T90-T98 & 7,1 & 5,6 & 5,4 & 5,5 & 6,9 & 6,5 & 8,6 & 6,9 & 8,5 & 7,1 & 6,5 & 8,4 & 6,9 & 6,8 \\
\hline $120-\mid 25$ & 6,7 & 6,4 & 9,3 & 3,7 & 6,5 & 8,2 & 11,3 & 10,5 & 6,8 & 5,7 & 6,7 & 8,0 & 6,5 & 6,7 \\
\hline |10-I15 & 6,0 & 5,9 & 6,6 & 3,9 & 7,7 & 6,5 & 5,8 & 9,7 & 6,8 & 6,3 & 7,2 & 5,9 & 5,8 & 6,2 \\
\hline S30-S39 & 6,3 & 4,9 & 6,9 & 4,7 & 5,8 & 5,2 & 6,2 & 6,9 & 9,4 & 4,0 & 7,0 & 11,2 & 5,1 & 6,2 \\
\hline S70-S79 & 5,5 & 5,6 & 6,0 & 6,2 & 5,8 & 6,5 & 6,2 & 7,5 & 7,8 & 4,6 & 6,7 & 12,9 & 7,3 & 6,0 \\
\hline Outros & 122,7 & 112,3 & 170,2 & 122,4 & 110,5 & 135,6 & 137,5 & 157,0 & 120,6 & 100,8 & 148,6 & 174,1 & 119,1 & 124,8 \\
\hline Total & 435,7 & 402,8 & 590,0 & 447,8 & 417,4 & 518,5 & 544,8 & 576,0 & 496,1 & 405,9 & 552,2 & 673,7 & 422,6 & 455,2 \\
\hline
\end{tabular}

${ }^{*}$ A população de estudo corresponde à média dos vínculos empregatícios declarados pelos empregadores na CNAE-Seção F-Construção no período: 1.784.772 vínculos

Agrupamentos CID-10 - Descrição: M40-M54 - Dorsopatias; S60-S69 - Traumatismos do punho e da mão; S80-S89 - Traumatismos do joelho e da perna; K40-K46 - Hérnias; S90-S99 - Traumatismos do tornozelo e do pé; M00-M25 - Artropatias; M60-M79 - Outros transtornos dos tecidos moles; S50-S59- Traumatismos do cotovelo e do antebraço; S40-S49- Traumatismos do ombro e do braço; F10-F19-Transtornos mentais e comportamentais devidos ao uso de substância psicoativa; S00-S09-Traumatismos da cabeça; 180-189- Doenças das veias, dos vasos linfáticos e dos gânglios linfáticos, não classificadas em outra parte; F30-F39 - Transtornos do humor (afetivos); C00-C97 - Neoplasias (tumores) malignas(os); T90-T98 - Sequelas de traumatismos, de intoxicações e de outras consequências das causas externas; I20-I25 - Doenças isquêmicas do coração; I10-I15 - Doenças hipertensivas; S30-S39 - Traumatismos do abdome, do dorso, da coluna lombar e da pelve; S70-S79 - Traumatismos do quadril e da coxa; Classes CNAE - Descrição: 4120 - Construção de edifícios; 4211 - Construção de rodovias e ferrovias; 4212 - Construção de obras de arte especiais; 4221 - Obras para geração e distribuição de energia elétrica e para telecomunicações; 4222 - Construção de redes de abastecimento de água, coleta de esgoto e construções correlatas; 4292 - Montagem de instalações industriais e de estruturas metálicas; 4312 - Perfurações e sondagens; 4313 - Obras de terraplanagem; 4321 - Instalações elétricas; 4322 - Instalações hidráulicas, de sistemas de ventilação e refrigeração; 4329 - Obras de instalações em construções não especificadas anteriormente; 4330 - Obras de acabamento 
Ao se buscar um maior detalhamento das causas diagnósticas dos benefícios (categoria CID-10) e sua relação com o sexo e a idade do trabalhador incapacitado, verificou-se que a variável idade apresentou relação direta com o aumento da prevalência de $\mathrm{BAD}$, independente do sexo, até a faixa etária de 50-59 anos de idade. (Tabela 4). Ao se considerar o total das categorias diagnósticas, independente do sexo, também ocorreu aumento da prevalência de BAD com a idade (dados não tabulados).

Em razão das diferentes atividades exercidas por homens e mulheres na Construção, foram encontradas diferenças substanciais na distribuição das prevalências entre os sexos e categorias diagnósticas. No geral, a categoria mais prevalente foi a Dorsalgia, com taxa pouco superior à Fratura ao nível do punho e da mão, sendo que essas duas categorias de causas diagnósticas representaram 13,2\% do total de casos (Tabela 4).

A partir da soma das prevalências de categorias de Doenças osteomusculares por cada faixa etária e sexo, verificou-se para ambos os sexos a mesma relação observada quanto à tendência geral, aumento da prevalência de BAD até os 59 anos (Tabela 4).
Com relação à idade e às categorias do grupo Lesões, entre os homens a maior prevalência foi observada na faixa etária de 20-29 anos, com gradativa queda com o avanço da idade. Entre as mulheres a situação geral é quase que inversa no conjunto dessas categorias. Houve aumento do número de Lesões até os 59 anos. A topografia das lesões também sofreu influência do sexo; enquanto entre os homens a prevalência de lesões nos membros superiores foi $22,2 \%$ maior que nos membros inferiores, entre as mulheres ocorre o contrário, as lesões de membros inferiores foram $35,4 \%$ maior do que superiores. Esses valores são obtidos avaliando-se as relações entre as somas das prevalências das categorias relacionadas a membros superiores (S42, S52 e S62) e inferiores (S82, S83 e S92), para homens e mulheres (Tabela 4).

Os BAD devido à Hérnia inguinal, quarta categoria mais prevalente, predominaram fortemente entre os homens, havendo aumento da prevalência com o avanço da idade em ambos os sexos (Tabela 4). A categoria mais prevalente dentre as Doenças mentais foi a dos Transtornos mentais e comportamentais devidos ao uso de múltiplas drogas e ao uso de outras substâncias psicoativas. Essa categoria prevaleceu entre homens com idade entre 20 e 40 anos, sendo que as

Tabela 4 Prevalência de benefícios auxílio-doença no ramo da Construção (por 10 mil vínculos)* segundo faixa etária e categoria CID-10 - Brasil - 2009

\begin{tabular}{|c|c|c|c|c|c|c|c|c|c|c|c|c|c|c|c|}
\hline \multirow{4}{*}{$\begin{array}{c}\text { Categoria } \\
\text { CID-10 }\end{array}$} & \multicolumn{14}{|c|}{ Sexo } & \multirow{4}{*}{ Total } \\
\hline & \multirow{2}{*}{\multicolumn{6}{|c|}{$\begin{array}{r}\text { Masculino } \\
\text { Faixa etária (anos) }\end{array}$}} & \multirow{3}{*}{ Total } & \multirow{2}{*}{\multicolumn{7}{|c|}{$\begin{array}{r}\text { Feminino } \\
\text { Faixa etária (anos) }\end{array}$}} & \\
\hline & & & & & & & & & & & & & & & \\
\hline & $<20$ & $20-29$ & $30-39$ & $40-49$ & $50-59$ & $\geq 60$ & & $<20$ & $20-29$ & $30-39$ & $40-49$ & 50-59 & $\geq 60$ & Total & \\
\hline M54 & 2,0 & 8,1 & 24,4 & 46,7 & 76,6 & 79,6 & 32,5 & - & 8,1 & 20,1 & 32,4 & 87,4 & 44,4 & 22,7 & 30,9 \\
\hline S62 & 41,2 & 38,4 & 33,6 & 27,0 & 24,7 & 12,8 & 31,9 & 6,9 & 7,2 & 5,5 & 6,6 & 17,0 & 6,3 & 7,2 & 29,0 \\
\hline S82 & 24,3 & 27,3 & 23,7 & 24,5 & 22,3 & 13,0 & 24,5 & 16,1 & 10,6 & 10,5 & 13,6 & 19,6 & 19,0 & 12,1 & 22,8 \\
\hline K40 & 2,4 & 10,7 & 14,5 & 22,6 & 36,9 & 37,4 & 18,5 & - & 1,1 & 2,1 & 3,5 & 5,4 & - & 2,1 & 16,7 \\
\hline S52 & 17,8 & 16,0 & 15,6 & 16,2 & 16,6 & 9,1 & 15,9 & - & 3,4 & 6,7 & 5,9 & 22,3 & 6,3 & 6,3 & 14,6 \\
\hline S92 & 11,3 & 15,6 & 14,5 & 17,2 & 14,7 & 13,0 & 15,3 & 4,6 & 8,5 & 11,1 & 9,1 & 10,7 & 19,0 & 9,6 & 14,5 \\
\hline M51 & 1,6 & 3,1 & 11,5 & 21,8 & 31,0 & 34,2 & 14,3 & - & 2,0 & 6,9 & 19,5 & 33,0 & 19,0 & 9,4 & 13,6 \\
\hline $\mathrm{S} 42$ & 14,6 & 13,2 & 11,9 & 11,6 & 9,4 & 4,1 & 11,7 & 4,6 & 5,0 & 4,6 & 3,5 & 5,4 & - & 4,6 & 10,8 \\
\hline M23 & 2,8 & 7,2 & 10,5 & 10,7 & 12,3 & 7,4 & 9,6 & - & 2,5 & 1,9 & 5,6 & 10,7 & - & 3,4 & 8,8 \\
\hline S83 & 3,2 & 9,8 & 9,6 & 8,5 & 7,3 & 3,0 & 8,9 & - & 2,9 & 3,1 & 1,7 & 5,4 & - & 2,8 & 8,1 \\
\hline M75 & - & 2,0 & 4,7 & 9,8 & 18,6 & 25,3 & 7,3 & - & 2,5 & 7,3 & 20,9 & 32,1 & 25,3 & 10,0 & 7,4 \\
\hline F19 & 1,2 & 10,6 & 9,4 & 4,0 & 1,3 & 0,2 & 7,1 & - & 0,7 & 1,3 & 0,7 & - & - & 0,8 & 6,4 \\
\hline Outros & 113,2 & 170,9 & 229,2 & 332,4 & 505,0 & 571,1 & 278,6 & 46,1 & 169,3 & 268,3 & 436,6 & 582,7 & 506,9 & 283,4 & 271,7 \\
\hline Total & 235,8 & 333,0 & 413,1 & 552,9 & 776,9 & 810,2 & 476,3 & 78,4 & 223,8 & 349,4 & 559,7 & 831,6 & 646,3 & 374,5 & 455,2 \\
\hline
\end{tabular}

* A população de estudo corresponde à média dos vínculos empregatícios declarados pelos empregadores na CNAE-Seção F-Construção no período: 1.784.772 vínculos

Categorias CID-10 - Descrição: M54 - Dorsalgia; S62 - Fratura ao nível do punho e da mão; S82 - Fratura da perna; K40 - Hérnia inguinal; S52 - Fratura do antebraço; S92 - Fratura do pé (exceto tornozelo); M51 - Outros transtornos de discos invertebrais; S42 - Fratura do ombro e do braço; M23 - Transtornos internos dos joelhos; S83 - Luxação, entorse e distensão das articulações e dos ligamentos dos joelhos; M75 - Lesões do ombro; F19 - Transtornos mentais e comportamentais devidos ao uso de múltiplas drogas e ao uso de outras substâncias psicoativas 
prevalências em outras faixas etárias, para homens e mulheres, foram pouco expressivas (Tabela 4).

\section{Discussão}

O presente estudo estimou a prevalência de Benefícios Auxílio-Doença (BAD) entre trabalhadores do ramo Construção no Brasil, em 2009, analisados segundo sua relação com a causa diagnóstica, ramo de atividade econômica (no nível classe), espécie de benefício, sexo e idade dos trabalhadores que receberam benefícios. As diferentes metodologias utilizadas em estudos de incapacidade para o trabalho, além dos diversos sistemas de concessão de benefícios, dificultam a comparação desses dados com os da literatura, sobretudo no ramo Construção.

A taxa de prevalência de incapacidade para o trabalho encontrada neste estudo para o ramo da Construção (4,6\%) foi pouco superior à encontrada para o conjunto da população empregada no Brasil em 2008 (<4,3\%), no entanto esta foi menor do que as apresentadas por ramos de atividade como Esgoto e atividades relacionadas (24,0\%), Fabricação de produtos de madeira $(7,6 \%)$ e Fabricação de móveis (6,3\%) (BARBOSA-BRANCO; SOUZA; STEENSTRA, 2011). Considerando os riscos existentes nas atividades de Construção (SOROCK; SMITH; GOLDOFT, 1993; LIPSCOMB; DEMENT; RODRIGUEZ-ACOSTA, 2000; JEONG, 1998; CATTLEDGE; HENDRICKS; STANEVICH, 1996; BURKHART et al., 1993), os resultados deste estudo apontam para possíveis mecanismos de subnotificação/demanda previdenciária.

A subnotificação no registro de agravos à saúde relacionados ao trabalho é um fenômeno mundial, tendo sido alvo de estudos científicos que registraram altas taxas nos Estados Unidos (LEIGH et al., 1997), Inglaterra (SOLOMON, 2002) e Espanha (GARCÍA GÓMEZ; GIL LÓPEZ, 1996). Estudos nacionais verificaram a subnotificação de acidentes e doenças do trabalho por meio do sistema de Comunicação de Acidentes de Trabalho - CAT (CORDEIRO et al., 2005; SOUZA et al., 2008), sendo esta estimada em 79,5\% para uma cidade do estado de São Paulo (CORDEIRO et al., 2005), com destaque para a subnotificação de acidentes de trabalho típicos devidos às causas externas (SOUZA et al., 2008), principal grupo diagnóstico para incapacidade laboral de origem acidentária verificada neste estudo.

Até o ano de 2007, os acidentes de trabalho e as doenças do trabalho no Brasil eram registrados por meio da CAT e se restringiam, em sua grande maioria às Lesões, uma vez que a emissão da CAT dependia, quase que exclusivamente, do empregador, o qual, em geral, somente realizava o procedimento nos casos de Lesões ocorridas durante a realização das atividades laborais, por ser fato inegável. Quando o trabalhador incapacitado para o trabalho passa a receber BAD por motivo acidentário, independente da duração, este adquire direitos como a estabilidade no emprego por período mínimo de um ano após seu retorno ao trabalho, a continuidade do depósito pelo empregador do Fundo de Garantia do Tempo de Serviço (FGTS), e a continuidade da contagem de tempo de serviço para aposentadoria de forma ininterrupta durante seu afastamento do trabalho (WÜNSCH FILHO, 1999). A partir da instituição do Nexo Técnico Epidemiológico Previdenciário (NTEP), em abril de 2007, as doenças ganharam peso na caracterização acidentária dos benefícios auxílio-doença, mas é possível que o perfil dos trabalhadores da construção e a elevada predominância do sexo masculino no ramo possam ter impactado ainda mais as taxas de subnotificação, uma vez que esses trabalhadores tendem a apresentar maior resistência à procura por serviços de saúde (GOMES; NASCIMENTO; ARAÚJO, 2007).

Após o aumento da caracterização de benefícios acidentários, observado com a introdução do NTEP, houve em 2008 uma aparente estabilização das taxas tanto dos benefícios previdenciários quanto dos acidentários, sendo possível que as empresas tenham adotado medidas internas visando evitar o afastamento do trabalhador pelo INSS em caso de incapacidade para o trabalho, uma vez que esses registros iriam influenciar na alíquota de impostos pagos a partir da introdução do Fator Acidentário de Prevenção (FAP), cuja metodologia já era conhecida pelos empregadores e sabia-se que o quadro epidemiológico apresentado pelos trabalhadores serviria de base para sua definição. Portanto, se antes do NTEP o desafio era combater a subnotificação do registro dos acidentes do trabalho por meio da CAT, a partir de 2009, ano de introdução do FAP, o desafio passa a ser combater a subnotificação da incapacidade para o trabalho como um todo.

A hipótese de que as empresas se anteciparam à implantação do FAP é reforçada ao se analisarem os dados sobre incapacidade para o trabalho no Brasil no ano de 2008 (BARBOSA-BRANCO; SOUZA; STEENSTRA, 2011). Nesse ano a Construção de edifícios (CNAE divisão 41) apresentou a terceira maior incidência ajustada quanto às Lesões $(287,9)$, atrás apenas dos ramos de Esgotos e Manufatura de madeira, valor bem maior que a prevalência encontrada no presente estudo. Ainda em comparação com os dados do mesmo estudo (BARBOSA-BRANCO; SOUZA; STEENSTRA, 2011), verifica-se que, em 2008, a razão de incidência para Lesões entre os sexos mostrou sobreprevalência masculina aproximadamente duas vezes maior para as CNAE-Divisão 41 e 42. As causas da ocorrência de subnotificação de incapacidade para o trabalho foram objeto de estudo internacional (UNITED STATES HOUSE OF REPRESENTATIVES, 2008), que apontou 
associação com os seguintes fatores: grande número de trabalhadores no mercado informal; a dificuldade em se caracterizar a relação entre o adoecimento e o trabalho, em especial para as Doenças osteomusculares; o desconhecimento do sistema de benefícios por empregados e empregadores; e a relutância do trabalhador em solicitar o benefício aliada ao desencorajamento provocado pelo empregador. Esse estudo (UNITED STATES HOUSE OF REPRESENTATIVES, 2008) indica que o fator mais preocupante está ligado à atitude dos empregadores em não notificar os eventos, uma vez que baixas taxas de adoecimento e acidentes com os trabalhadores diminuem as chances de uma fiscalização trabalhista; diminuem os gastos com os afastamentos por incapacidade para o trabalho; aumentam as chances de se conseguir contratos governamentais; e melhoram a imagem da empresa perante clientes, acionistas e comunidade em geral.

Nesse processo de promoção da subnotificação de incapacidade para o trabalho, os empregadores se utilizam de alguns métodos para que os registros não ocorram (CONWAY; SVENSON, 1998), entre os quais se encontram a intimidação direta ao empregado, com ameaças de perda do emprego, cortes salariais, supressão de horas extras e oportunidades de promoção, e assédio moral; o retorno precoce ao trabalho do empregado incapacitado, ainda que para o exercício de "trabalho leve"; o oferecimento de primeiros-socorros por meio de equipe médica própria, instruída a não promover o registro de acidentes de menor gravidade; políticas de abono de faltas em que os empregados dispõem de certa quantidade de dias de folga para quaisquer usos; falso incentivo às práticas laborais seguras por meio de folgas ou recompensas monetárias para as equipes de trabalho que não registraram acidentes e afastamentos; intimidação por meio de exames toxicológicos em caso de acidentes; terceirização de mão de obra para atividades de maior risco e a contratação de "autônomos" em substituição de empregados regulares, uma vez que nesse caso o registro de acidentes não estaria associado ao contratante (CONWAY; SVENSON, 1998). Essas práticas podem ser observadas no ramo da Construção e são agravadas devido ao grande número de trabalhadores em atividades não especializadas, cujo temor em perder o emprego se deve à grande facilidade de reposição.

A análise da potencial influência do sexo na prevalência de incapacidade para o trabalho (benefício auxílio-doença) mostra que a maior $(30,0 \%)$ prevalência de BAD concedidos ao sexo masculino nesse ramo de atividade, quando comparada aos trabalhadores femininos, vai ao encontro da maioria dos resultados nacionais (PIHA et al., 2010; LAAKSONEN et al., 2010; ILDEFONSO; BARBOSA-BRANCO; ALBUQUERQUEOLIVEIRA, 2009; BRANCO; ILDEFONSO, 2012) e internacionais (OCCUPATIONAL SAFE \& HEALTH
ADMINISTRATION, 1999), que incluem trabalhadores da Construção no campo da incapacidade para o trabalho. Conhecendo-se a influência do ambiente de trabalho no perfil de adoecimento dos trabalhadores (LAAKSONEN et al., 2010), a maior prevalência de BAD entre os homens nesse ramo pode estar associada à maior exposição aos riscos ocupacionais comumente presentes na construção (SOROCK; SMITH; GOLDOFT, 1993; LIPSCOMB; DEMENT; RODRIGUEZ-ACOSTA, 2000; JEONG, 1998; CATTLEDGE; HENDRICKS; STANEVICH, 1996; BURKHART et al., 1993). Apesar da grande variação nas taxas de incapacidade para o trabalho apresentada em diferentes países, alguns autores (NELSON et al., 2005) concluem que, em países em desenvolvimento, os trabalhadores do sexo masculino estão mais expostos aos riscos ocupacionais, além de estarem mais expostos à violência social e acidentes de trânsito (BARBOSA-BRANCO; SOUZA; STEENSTRA, 2011).

Quando analisados os grupos diagnósticos, homens e mulheres apresentaram quadros de adoecimento específicos. A elevada sobretaxa de prevalência masculina devido a Doenças digestivas relacionadas ao trabalho pode decorrer de fatores como o tipo de alimentação ofertada, condições de higiene pessoal (banheiros, pias, vestuário), pressões de ritmo de trabalho e produtividade. Esses fatores podem contribuir para os agravos digestivos nesses trabalhadores (RINGEN; SEEGAL; WEEKS, 1998; BRODKIN; LEE; REDLICH, 1994), entretanto no presente estudo nota-se que as características das atividades relacionadas ao esforço físico e carregamento de peso podem ter influenciado diretamente na maior prevalência de Hérnia inguinal entre os homens.

Revisão sistemática (SVENDSEN et al., 2013) avaliando as evidências da relação entre exposição ocupacional e Hérnia inguinal em trabalhos com moderada a grande exigência mecânica conclui que apesar de ser uma doença comum entre homens, e das limitadas evidências epidemiológicas, trabalhos com grande exigência física podem aumentar os riscos de um prognóstico desfavorável. Uma importante parte dessa sobretaxa de Doenças digestivas observada no sexo masculino foi influenciada pelo elevado número de auxílio-doença decorrente de Hérnias (K40-K46), em particular, das Hérnias inguinais, mais prevalentes entre os homens (7,5:1) (SVENDSEN et al., 2013).

No ramo da Construção, outro potencial fator de risco para as Doenças digestivas é a comorbidade decorrente dos Transtornos mentais e comportamentais devidos ao uso de álcool, também mais prevalente no sexo masculino. Apesar dos resultados do presente estudo não apresentarem os Transtornos mentais e comportamentais devidos ao uso de álcool entre as categorias diagnósticas mais prevalentes, estudos nacionais (BARBOSA-BRANCO; BÜLTMANN; STEENSTRA, 
2012) e internacionais (HOFFMANN; BRITTINGHAM; LARISON, 1996; SUBSTANCE ABUSE AND MENTAL HEALTH SERVICES ADMINISTRATION, 2007; HARFORD; BROOKS, 1992) mostraram que o ramo da Construção figura entre os que mais apresentam trabalhadores com esse tipo de agravo. A baixa remuneração dos trabalhadores, como ocorre no ramo da Construção, se apresenta como fator de risco para o uso abusivo de álcool (HWANG et al., 2005). A elevada prevalência de doenças digestivas verificadas por este estudo, juntamente com a conhecida relação entre abuso de álcool e doenças digestivas (BRODKIN; LEE; REDLICH, 1994), sugere potenciais desvios de classificação diagnóstica em favor das consequências clínicas de agravos como Transtornos mentais e comportamentais devidos ao uso de álcool. Empiricamente, verifica-se que trabalhadores da Construção ingerem grandes quantidades de álcool, inclusive em dias de trabalho, entretanto a pressão pelo cumprimento de metas de produção faz com que, muitas vezes, haja tolerância a esse comportamento por parte de encarregados e demais membros da equipe de produção.

As mais altas prevalências de Transtornos mentais e comportamentais devidos ao uso de múltiplas drogas e ao uso de outras substâncias psicoativas - principal causa clínica entre as doenças mentais na Construção - encontradas entre trabalhadores com menos de 40 anos encontram-se em concordância com os achados de Barbosa-Branco, Bültmann e Steenstra (2012) para o conjunto dos trabalhadores empregados em 2008. No ramo da Construção, trabalhadores mais jovens são mais exigidos fisicamente e, em grande parte, dependem de sua força física para a prática laboral, mas essa fase conjuga fatores sociais como a maior propensão de jovens ao uso de substâncias psicoativas e os momentos de estabelecimento no emprego e constituição familiar, estressores que podem influir no uso dessas substâncias. Estudo internacional (WEBB et al., 2005) mostrou que homens com idade entre 26 e 34 anos tem duas vezes mais chance de apresentarem um quadro de uso severo de álcool do que aqueles com idade ente 18 e 25 anos, constituindose fatores de risco para esse uso a baixa escolaridade e a relação parental com crianças.

Em comparação com a prevalência de BAD para trabalhadores brasileiros em 2008 (BARBOSA-BRANCO; SOUZA; STEENSTRA, 2011), o ramo da Construção, em 2009, mostrou maior prevalência em relação às Doenças do aparelho circulatório, com destaque para Doenças das veias; Doenças isquêmicas do coração e Doenças hipertensivas. Essa maior prevalência se deve ao fato da predominância masculina no ramo, uma vez que esse tipo de adoecimento acomete mais os homens (LAAKSONEN et al., 2010; SALA; MENDES, 2010).

A influência da idade no perfil epidemiológico da incapacidade laboral, de forma geral, seguiu a tendência já descrita em estudos anteriores (ROELEN et al., 2009; BARBOSA-BRANCO; SOUZA; STEENSTRA, 2011; VIEIRA; ALBUQUERQUE-OLIVEIRA; BARBOSABRANCO, 2011; ILDEFONSO; BARBOSA-BRANCO; ALBUQUERQUE-OLIVEIRA, 2009; PRANSKY et al., 2006), os quais mostraram que as taxas de afastamento aumentam com a idade, podendo influenciar na duração dos afastamentos, pois trabalhadores com maior idade podem precisar de mais tempo para se recuperar de agravos e retornarem ao trabalho (ALMEIDA; BARBOSA-BRANCO, 2011).

O aumento da prevalência de Doenças osteomusculares com a idade já foi mostrado em estudos anteriores (BARBOSA-BRANCO; SOUZA; STEENSTRA, 2011; VIEIRA; ALBUQUERQUE-OLIVEIRA; BARBOSABRANCO, 2011; PRANSKY et al., 2006), entretanto a comparação da razão de prevalência desse tipo de adoecimento entre trabalhadores com idades $\geq 40$ anos e $<40$ anos (RP 3,2; dados não mostrados), com o geral da população empregada no Brasil (RP 2,6) (BARBOSA-BRANCO; SOUZA; STEENSTRA, 2011), aponta para a existência de grande exigência física nas atividades da Construção.

A tendência geral da prevalência de Lesões verificada neste estudo foi inversa ao comportamento apresentado pelas Doenças osteomusculares, pois a maior taxa foi encontrada entre trabalhadores com idade abaixo de 40 anos, em especial para diagnósticos relacionados aos membros superiores dos homens. Apesar da exigência física e da exposição aos riscos ocupacionais decrescer pouco com a idade, a experiência adquirida ao longo dos anos de profissão aparenta ser um fator de proteção para esses trabalhadores (ALMEIDA; BARBOSA-BRANCO, 2011), inclusive devido à maior chance destes terem recebido treinamento adequado para o exercício da tarefa.

De modo geral, a maior prevalência de Lesões nos membros superiores dos homens relaciona-se ao trabalho, enquanto entre as mulheres a maior prevalência desses agravos ocorreu nos membros inferiores, e pode estar ligada aos acidentes de percurso, acidentes domésticos e quedas. A razão de incidência de Lesões em relação à idade dicotomizada encontrada em 2008 (BARBOSA-BRANCO; SOUZA; STEENSTRA, 2011) para trabalhadores da construção mostrou diferenças de até $20 \%$ para trabalhadores mais idosos, de modo que em 2009 pode ter havido maior subnotificação de Lesões em trabalhadores mais idosos, ou ainda apontar para uma mudança no perfil de contratação de trabalhadores. O setor da Construção Civil no Brasil vem passando por uma grande transformação na última década, saindo de um período de estagnação, com poucos investimentos, para um período com grandes obras em andamento e fortes investimentos imobiliários (MELLO; AMORIM, 2009), sendo possível uma maior contratação de 
jovens para se evitarem os efeitos de adoecimentos relacionados com a idade, como no caso de Hérnia inguinal, de grande prevalência e cujo aumento da ocorrência com o avanço da idade foi exaustivamente descrito na literatura (SVENDSEN et al., 2013).

Em relação à influência do ramo de atividade no quadro de adoecimento dos trabalhadores estudados, os dados sugerem relação entre os fatores de risco presentes nas atividades típicas realizadas por cada ramo e as causas diagnósticas mais prevalentes.

A maior caracterização da relação dos agravos com o trabalho encontrada no ramo da Construção, quando comparada a outros ramos de atividades (BARBOSA-BRANCO; SOUZA; STEENSTRA, 2011), pode decorrer da grande contribuição das Lesões, cuja elevada prevalência tanto entre os BAD previdenciários quanto os acidentários decorre, em grande parte, das características e condições de trabalho encontradas nesses ramos de atividade (CNAE-Divisão 41, 42, 43), assim como a fatores gerais representados pelas violências urbana e no trânsito (BARBOSA-BRANCO; SOUZA; STEENSTRA, 2011). Nesse sentido, contribuem para o aumento da prevalência de Lesões as atividades com alta demanda de esforço físico e o fato de que no Brasil os afastamentos devido a lesões ocorridas no trajeto entre casa e trabalho serem considerados como acidentários.

Os dados obtidos sobre a prevalência de Lesões e Doenças osteomusculares corroboram aqueles descritos na literatura (SOROCK; SMITH; GOLDOFT, 1993; LIPSCOMB; DEMENT; RODRIGUEZ-ACOSTA, 2000; JEONG, 1998; CATTLEDGE; HENDRICKS; STANEVICH, 1996; BURKHART et al., 1993), acerca dos riscos e características desse ramo de atividade, e reforçam a necessidade de maior fiscalização quanto ao cumprimento da legislação relativa à saúde e segurança ocupacional em atividades do ramo da Construção, uma vez que o grande número de afastamentos relacionados ao trabalho devido às Lesões pode estar relacionado à ineficácia da gestão de segurança do trabalho na Construção.

Estudo brasileiro (MIRANDA; DIAS, 2004) apontou a baixa qualidade técnica em programas obrigatórios de gestão de saúde e segurança ocupacional que devem ser desenvolvidos pelos empregadores, como o Programa de Prevenção de Riscos Ambientais (PPRA) e o Programa de Controle Médico de Saúde Ocupacional (PCMSO). Segundo os autores, isso decorre da ineficiência da fiscalização estatal, que não possui recursos humanos suficientes para o desenvolvimento das ações, além de que o quadro ora existente carece de treinamento adequado e atualização técnica. O estudo apontou ainda a necessidade de estimular maior controle social, a ser exercido por empregados e seus representantes no âmbito sindical.
Estudo avaliando as percepções de trabalhadores do ramo da Construção sobre os riscos ocupacionais a que estariam expostos (SAURIN; RIBEIRO, 2000) identificou diversas necessidades de melhoria gerencial, as quais influenciam de modo direto ou indireto a segurança no trabalho. Foi verificado que tanto gestores quanto operários, além de não possuírem sugestões para a melhoria das condições de segurança, tenderam a culpar os trabalhadores pela ocorrência de acidentes, de modo que é necessário estender as ações de treinamento e capacitação a todos os níveis da empresa. Segundo os autores, quando a segurança do trabalho é colocada em segundo plano, ocorrem implicações negativas diretas como treinamento inadequado dos trabalhadores quanto aos riscos laborais, fornecimento inadequado e utilização incorreta de equipamentos de proteção individual (EPI), bem como ineficácia da Comissão Interna de Prevenção de Acidentes (CIPA), que, na Construção, enfrenta barreiras adicionais em razão da baixa escolaridade dos trabalhadores e da alta rotatividade no ramo (LAAKSONEN et al., 2010; BARBOSA-BRANCO; SOUZA; STEENSTRA, 2011; DEPARTAMENTO INTERSINDICAL DE ESTATÍSTICA E ESTUDOS SOCIOECONÔMICOS, 2001; RINGEN; SEEGAL; WEEKS, 1998; SAURIN; RIBEIRO, 2000), e reflete a falta de controle social ao não cumprir atribuições como a produção de mapas de riscos ambientais, que em geral, quando são desenvolvidos, não contam com a participação dos empregados (MIRANDA; DIAS, 2004).

O ramo Obras de acabamento, que mostrou a maior prevalência de BAD em geral, e também liderou a taxa em relação às Lesões, dedica-se aos serviços de acabamento, ou seja, todas as atividades que contribuem para a conclusão da construção bem como para a sua manutenção, tais como: pintura, revestimentos, polimento, colocação de esquadrias e vidros, limpeza de fachadas, colocação de pisos etc. Existem riscos ocupacionais de acidentes devido à utilização de ferramentas manuais, equipamentos de corte e acabamento de materiais, trabalhos em altura com utilização de andaimes e balancins, posturas antiergonômicas e manuseio de tintas e vernizes. A fase de acabamento de uma obra, que normalmente é acompanhada por pressões por parte do empregador para aceleração do prazo de entrega, pode vir a ser o momento em que o trabalhador é levado a se preocupar menos com os riscos de acidentes, e por vezes adota práticas inseguras que culminam em elevado número de acidentes com frequente incapacidade para o trabalho.

A maior prevalência de Traumatismos da mão e punho no ramo Perfurações e sondagens pode estar associada à grande exigência de trabalhos manuais com ferramentas na montagem e desmontagem de sistemas de perfuração e sondagem, além da utilização essencial de trados manuais. 
O correto dimensionamento dos equipamentos de proteção coletiva (EPC), a fiscalização e o uso adequado de EPI como luvas, máscaras, calçados, capacetes e cintos de segurança e o conhecimento dos riscos específicos da tarefa (treinamento) podem contribuir positivamente para a redução desse tipo de ocorrência.

Em relação às Doenças osteomusculares, a distribuição dos agrupamentos no ramo Construção foi semelhante àquela apresentada por Vieira, Albuquerque-Oliveira e Barbosa-Branco (2011), no qual predominaram as Dorsalgias, Outros transtornos de discos invertebrais, Transtornos internos dos joelhos, Sinovites e tenossinovites e Lesões do ombro. Vale ressaltar que o trabalhador da Construção comumente desenvolve atividades em condições antiergonômicas que representam importantes riscos para o desenvolvimento/agravamento das doenças osteomusculares, principalmente aquelas que afetam a coluna e as articulações. Considerando esses riscos é possível supor que essas taxas sejam ainda mais elevadas.

A grande diferença encontrada entre a prevalência de Dorsopatias entre os ramos Construção de obras de arte e Instalações hidráulicas pode decorrer das diferentes atividades realizadas por essas classes. A CNAE Construção de obras de arte compreende atividades de construção e recuperação de pontes, viadutos, elevados, passarelas e outros, além da construção de túneis (urbanos, em rodovias, ferrovias, subterrâneos), sendo comum a realização de movimentos altamente repetitivos e com elevada exigência postural, principalmente em atividades de armação de ferragens, nas quais predominam movimentos de torção do punho e posturas inclinadas para frente ou totalmente inclinadas $\left(>90^{\circ}\right)$. O ramo Instalações hidráulicas atua na instalação, alteração, manutenção e reparo em todos os tipos de construções de sistemas de aquecimento (coletor solar, gás e óleo), exceto elétricos; equipamentos hidráulicos e sanitários; ligações de gás; tubulações de vapor; de refrigeração central, quando não realizados pelo fabricante; e de ventilação mecânica controlada, de modo que o transporte manual de cargas é reduzido e predominam os movimentos finos de coordenação motora durante a utilização de ferramentas manuais.

Em termos gerais, apesar do ramo Construção de edifícios ser o mais representativo em número de trabalhadores e, consequentemente, o mais estudado na totalidade dos ramos da Construção, os adoecimentos que geraram afastamentos do trabalho nesse ramo não se refletiram em taxas de prevalência acentuadas. É possível supor que esse ramo, por suas características, seja mais fiscalizado pelos órgãos competentes e, portanto, receba mais investimentos e atenção às questões de saúde e segurança ocupacional.
A análise geral dos dados levantados por este estudo permite inferir a existência de grupos homogêneos de exposição aos riscos ocupacionais presentes em cada conjunto de atividades. Esses riscos associados à inadequada gestão dos mesmos podem estar contribuindo para o adoecimento dos trabalhadores. Um exemplo dessa constatação poderia ser verificado no ramo Obras de terraplanagem, no qual a grande exposição dos trabalhadores às poeiras e a utilização de equipamentos ruidosos e de grande porte podem ter influenciado a elevada prevalência de Doenças da pele e Doenças do ouvido nesse ramo.

Este estudo utilizou-se da taxa de prevalência de benefícios auxílio-doença como indicador para avaliar a influência do sexo, da idade e do ramo de atividade específico no quadro de incapacidade para o trabalho de empregados da Construção no Brasil em 2009, contribuindo de forma inédita para o estabelecimento do perfil de morbidade desses trabalhadores no país. A relação entre as atividades realizadas e as altas prevalências de grupos diagnósticos como Lesões e Doenças osteomusculares indica haver nexos causais entre atividades específicas e o quadro de incapacidade, ainda que parte dos adoecimentos não tenha sido reconhecida como de causa acidentária para a concessão de BAD. As evidências epidemiológicas deste estudo podem contribuir para elucidar questões científicas ainda não consolidadas, como a relação entre atividades com alta exigência física e o desenvolvimento de Doenças digestivas, em especial as Hérnias.

Em relação às limitações deste estudo, é possível citar a falta de controle quanto à recorrência de benefícios, que possivelmente pode ocorrer quando um mesmo trabalhador recebe um novo $\mathrm{BAD}$ pela mesma causa diagnóstica de benefício encerrado há mais de 60 dias. Apesar da recorrência de benefícios afetar o valor da prevalência calculada, estima-se que tal efeito seja minimizado pela magnitude dos dados analisados. Apesar das limitações, considera-se que a população de estudo foi suficientemente ampla para que, dentre os trabalhadores empregados, os resultados fossem representativos. Ressalta-se a qualidade dos bancos de dados utilizados que se destacam em termos de tamanho, homogeneidade e padronização de protocolos decorrente do sistema de concessão de benefícios.

\section{Conclusão}

Verificou-se influência do diagnóstico da incapacidade, do sexo e da idade do empregado sobre a prevalência e duração dos benefícios auxílio-doença previdenciário e acidentário.

A forte caracterização acidentária dos afastamentos relacionados às Lesões entre os homens mostrou que 
no âmbito ocupacional há sobre-exposição destes aos riscos do ambiente de trabalho, cujo gerenciamento tem sido ineficaz por parte dos empregadores. Estes, por sua vez, podem ter se aproveitado da ineficiente fiscalização promovida pelas autoridades competentes, que dispõem insuficientemente de recursos humanos e materiais.

Apesar de a idade contribuir para o aumento da prevalência de benefícios auxílio-doença, para as Lesões de membros superiores entre homens a idade apresentou-se como fator de proteção para esses trabalhadores, podendo-se atribuir o fato à maior chance em ter recebido treinamento adequado para o exercício das tarefas.

Ao se analisar o contexto legal dos benefícios auxíliodoença e as implicações (econômicas, trabalhistas, tributárias e outras) geradas, principalmente para os empregadores, a partir da adoção do Nexo Técnico Epidemiológico Previdenciário - NTEP e da iminente adoção do Fator Acidentário de Prevenção - FAP, verificou-se a possibilidade das empresas do ramo da Construção terem buscado diversos meios alternativos objetivando evitar o afastamento legal dos trabalhadores incapacitados, inclusive com práticas já verificadas em outros países. Portanto, ao passo que o NTEP permitiu a caracterização de doenças relacionadas ao trabalho de modo independente da emissão da CAT, em parte, também pode ter contribuído para o aprimoramento de mecanismos de subnotificação dos agravos à saúde dos trabalhadores. Nesse sentido, os trabalhadores da Construção apresentam-se evidentemente vulneráveis por conta de suas características de fragilidade socioeconômica e baixa representatividade sindical.

Para que se tenham melhorias no quadro de incapacidade para o trabalho dos trabalhadores estudados, torna-se indispensável desfazer os conceitos socialmente aceitos de que risco de morte, exposição ao perigo e condições de trabalho inadequadas são inerentes ao ramo da Construção.

\section{Contribuições de autoria}

Mello, T. A.: contribuição substancial no projeto e delineamento, levantamento de dados, análise e interpretação e elaboração do manuscrito. Barbosa-Branco, A.: contribuição substancial no projeto e delineamento, levantamento de dados, análise e interpretação; e contribuição importante na revisão crítica do manuscrito e aprovação final da versão a ser publicada.

\section{Referências}

ALMEIDA, P. C. A.; BARBOSA-BRANCO, A. Acidentes de trabalho no Brasil: prevalência, duração e despesa previdenciária dos auxílios-doença. Revista Brasileira de Saúde Ocupacional, São Paulo, v. 36, n. 124, p. 195-207, 2011. http://dx.doi.org/10.1590/S030376572011000200003.

BARBOSA-BRANCO, A.; SOUZA, W. R.; STEENSTRA, I. A. Incidence of work and non-work related disability claims in Brazil. American Journal of Industrial Medicine, New York, v. 54, n. 11, p. 858871, 2011. http://dx.doi.org/10.1002/ajim.20974. PMid:21630300

BARBOSA-BRANCO, A. B.; BÜLTMANN, U.; STEENSTRA, I. Sickness benefit claims due to mental disorders in Brazil: associations in a populationbased study. Cadernos de Saúde Pública, Rio de Janeiro, v. 28, n. 10, p. 1854-1866, 2012. http:// dx.doi.org/10.1590/S0102-311X2012001000005. PMid:23090166

BRANCO, A. B.; ILDEFONSO, S. A. G. Prevalência e duração dos benefícios auxílio-doença decorrentes de asma no Brasil em 2008. Jornal Brasileiro de Pneumologia, São Paulo, v. 38, n. 5, p. 550-558, 2012.
http://dx.doi.org/10.1590/S1806-37132012000500003. PMid:23147046

BRODKIN, C. A.; LEE, S.; REDLICH, C. A. Gastrointestinal disorders. In: ROSENSTOCK, L.; CULLEN, M. R. (Eds.). Textbook of clinical occupational and environmental medicine. Philadelphia: Saunders, 1994. p. 423-436.

BURKHART, G. et al. Job tasks, potential exposures, and health risks of laborers employed in the construction industry. American Journal of Industrial Medicine, New York, v. 24, n. 4, p. 413-425, 1993. http://dx.doi.org/10.1002/ajim.4700240407. PMid:8250061

CATTLEDGE, G. H.; HENDRICKS, S.; STANEVICH, R. Fatal occupational falls in the U.S. construction industry, 1980-1989. Accident Analysis and Prevention, Elmsford, v. 28, n. 5, p. 647-654, 1996. http://dx.doi.org/10.1016/0001-4575(96)00025-5. PMid:8899046

CONWAY, H.; SVENSON, J. Occupational injury and illness rates, 1992-96: why they fell. Monthly Labor Review, Washington, p. 36-58, nov. 1998. 
CORDEIRO, R. et al. Subnotificação de acidentes do trabalho não fatais em Botucatu, SP, 2002. Revista de Saúde Pública, São Paulo, v. 39, n. 2, p. 254-260, 2005. http://dx.doi.org/10.1590/S0034-89102005000200017. PMid:15895146

DEPARTAMENTO INTERSINDICAL DE ESTATÍSTICA E ESTUDOS SOCIOECONÔMICOS - DIEESE. Os trabalhadores e a reestruturação produtiva na construção civil brasileira. Série Estudos Setoriais, São Paulo, n. 12, 2001.

GARCÍA GÓMEZ, M.; GIL LÓPEZ, E. Los sistemas de información y la vigilancia en salud laboral. Revista Española de Salud Pública, Madrid, v. 70, n. 4, p. 393407, 1996. PMid:8998688.

GOMES, R.; NASCIMENTO, E. F.; ARAÚJO, F. C. Por que os homens buscam menos os serviços de saúde do que as mulheres? As explicações de homens com baixa escolaridade e homens com ensino superior. Cadernos de Saúde Pública, São Paulo, v. 23, n. 3, p. 565-574, 2007. http://dx.doi.org/10.1590/S0102311X2007000300015. PMid:17334571

HARFORD, T. C.; BROOKS, S. D. Cirrhosis mortality and occupation. Journal of Studies on Alcohol, New Brunswick, v. 53, n. 5, p. 463-468, 1992. PMid:1405639.

HOFFMANN, J. P.; BRITTINGHAM, A.; LARISON, C. Drug use among U.S. workers: prevalence and trends by occupation and industry categories. In: OFFICE OF APPLIED STUDIES. Substance Abuse and Mental Health Services Administration. Washington: Government Printing Office, 1996. (DHHS Publication, No. SMA 96-3089). Disponível em: < https://books.google.com.br/books?id=Z6vD U_2VZGoC\&lpg $=$ PR15\&ots $=$ pbhovcFkye\&dq $=$ Dr ug\%20use\%20among\%20U.S.\%20workers\%3A\%20 prevalence $\% 20$ and $\% 20$ trends\%20by\%20 occupation\%20and\%20industry\%20categories\&hl=pt$\mathrm{BR} \& \mathrm{pg}=\mathrm{PR} 1 \mathrm{\#}_{\mathrm{v}}=$ onepage $\& \mathrm{q}=$ Drug\%20use $\% 20$ among\%20U.S.\%20workers:\%20prevalence\%20 and\%20trends\%20by\%20occupation\%20and\%20 industry\%20categories\&f $=$ true $>$. Acesso em: 05 jan. 2015.

HWANG, S. W. et al. Age- and sex-specific income gradients in alcohol-related hospitalization rates in an urban area. Annals of Epidemiology, Raleigh, v. 15, n. 1, p. 56-63, 2005. http://dx.doi.org/10.1016/j. annepidem.2004.04.003. PMid:15571994

ILDEFONSO, S. A.; BARBOSA-BRANCO, A.; ALBUQUERQUE-OLIVEIRA, P. R. Prevalência de benefícios de seguridade social temporários devido a doença respiratória no Brasil. Jornal Brasileiro de Pneumologia, São Paulo, v. 35, n. 1, p. 44-53, 2009. http://dx.doi.org/10.1590/S1806-37132009000100007. PMid:19219330

JEONG, B. Y. Occupational deaths and injuries in the construction industry. Applied Ergonomics, Guildford, v. 29, n. 5, p. 355-360, 1998. http://dx.doi.org/10.1016/ S0003-6870(97)00077-X. PMid:9703349

LAAKSONEN, M. et al. Gender differences in sickness absence-the contribution of occupation and workplace. Scandinavian Journal of Work, Environment \& Health, Helsinki, v. 36, n. 5, p. 394403, 2010. http://dx.doi.org/10.5271/sjweh.2909. PMid:20213051

LEIGH, J. P. et al. Occupational injury and illness in the United States. Estimates of costs, morbidity, and mortality. Archives of Internal Medicine, Chicago, v. 157, n. 14, p. 1557-1568, 1997. http:// dx.doi.org/10.1001/archinte.1997.00440350063006. PMid:9236557

LIPSCOMB, H. J.; DEMENT, J. M.; RODRIGUEZACOSTA, R. Deaths from external causes of injury among construction workers in North Carolina, 1988-1994. Applied Occupational and Environmental Hygiene, Philadelphia, v. 15, n. 7, p. 569-580, 2000. http://dx.doi.org/10.1080/10473220050028394. PMid:10893793

MELLO, L. C. B. B.; AMORIM, S. R. L. O subsetor de edificações da construção civil no Brasil: uma análise comparativa em relação à União Europeia e aos Estados Unidos. Production, São Paulo, v. 19, n. 2, p. 388-399, 2009. http://dx.doi.org/10.1590/S010365132009000200013.

MIRANDA, C. R.; DIAS, C. R. PPRA/PCMSO: auditoria, inspeção do trabalho e controle social. Cadernos de Saúde Pública, Rio de Janeiro, v. 20, n. 1, p. 224-232, 2004. http://dx.doi.org/10.1590/S0102311X2004000100039. PMid:15029324

NELSON, D. I. et al. The global burden of selected occupational diseases and injury risks: Methodology and summary. American Journal of Industrial Medicine, New York, v. 48, n. 6, p. 400-418, 2005. http://dx.doi.org/10.1002/ajim.20211. PMid:16299700

OCCUPATIONAL SAFE \& HEALTH

ADMINISTRATION - OSHA. US Department of Labour. Women in the construction workplace: providing equitable safety and health protection. Washington: OSHA, 1999. Disponível em: <https:// www.osha.gov/doc/accsh/haswicformal.html >. Acesso em 04 set. 2013.

PIHA, K. et al. Interrelationships between education, occupational class, income and sickness absence. European Journal of Public Health, Oxford, v. 20, n. 3, p. 276-280, 2010. http://dx.doi.org/10.1093/eurpub/ ckp162. PMid:19843600

PRANSKY, G. S. et al. Length of disability prognosis in acute occupational low back pain claims. The Spine Journal, New York, v. 31, n. 6, p. 690-697, 2006. http:// dx.doi.org/10.1097/01.brs.0000202761.20896.02.

RINGEN, K.; SEEGAL, J. L.; WEEKS, J. L.

Constructión. In: STELLMAN, J. M. (Ed.).

Enciclopedia de Salud y Seguridad en el Trabajo. 
Geneva: International Labour Office, 1998. Disponível em: <http://www.insht.es/InshtWeb/Contenidos/ Documentacion/TextosOnline/EnciclopediaOIT/ tomo3/93.pdf>. Acesso em: 04 set. 2013.

ROELEN, C. A. et al. Trends in the incidence of sickness absence due to common mental disorders between 2001 and 2007 in the Netherlands. European Journal of Public Health, London, v. 19, n. 6, p. 625630, 2009. http://dx.doi.org/10.1093/eurpub/ckp090. PMid:19581376

SALA, A.; MENDES, J. D. V. Perfil da mortalidade masculina no Estado de São Paulo. Boletim Epidemiológico Paulista, São Paulo, v. 7, n. 82, p. 1525, 2010.

SANTANA, V. S.; OLIVEIRA, R. P. Saúde e trabalho na construção civil em uma área urbana do Brasil. Cadernos de Saúde Pública, Rio de Janeiro, v. 20, n. 3, p. 797-811, 2004. http://dx.doi.org/10.1590/S0102311X2004000300017. PMid:15263991

SAURIN, T. A.; RIBEIRO, J. L. D. Segurança no trabalho em um canteiro de obras: percepções dos operários e da gerência. Production, São Paulo, v. 10, n. 1, p. 5-17, 2000.

SERVIÇO SOCIAL DA INDÚSTRIA - SESI. Projeto SESI na Indústria da Construção: diagnóstico da mãode-obra do setor da construção civil. Brasília: SESI, 1998.

SOLOMON, C. Accidental injuries in agriculture in the UK. Occupational Medicine, Chicago, v. 52, n. 8, p. 461-466, 2002. http://dx.doi.org/10.1093/ occmed/52.8.461. PMid:12488516

SOROCK, G. S.; SMITH, E. O.; GOLDOFT, M. Fatal occupational injuries in the New Jersey construction industry, 1983 to 1989. Journal of Occupational Medicine, Chicago, v. 35, n. 9, p. 916-921, 1993. http:// dx.doi.org/10.1097/00043764-199309000-00015. PMid:8229344

SOUZA, N. S. S. et al. Doenças do trabalho e benefícios previdenciários relacionados à saúde, Bahia, 2000. Revista de Saúde Pública, São Paulo, v.
42, n. 4, p. 630-638, 2008. http://dx.doi.org/10.1590/ S0034-89102008000400008. PMid:18709240

SUBSTANCE ABUSE AND MENTAL HEALTH SERVICES ADMINISTRATION - SAMHSA. Office of Applied Studies. The NSDUH report: worker substance use by industry category. Rockville: Office of Applied Studies, 2007. Disponível em: < http://www.samhsa. gov/data/2k7/industry/worker.htm $>$. Acesso em: 04 set. 2013.

SVENDSEN, S. W. et al. Risk and prognosis of inguinal hernia in relation to occupational mechanical exposures-a systematic review of the epidemiologic evidence. Scandinavian Journal of Work, Environment $\&$ Health, Helsinki, v. 39, n. 1, p. 5-26, 2013. http:// dx.doi.org/10.5271/sjweh.3305. PMid:22643828

UNITED STATES HOUSE OF REPRESENTATIVES. A Majority Staff Report by the Committee on Education and Labor. Hidden tragedy: underreporting of workplace injuries and illnesses. Washington: U.S. Government Printing Office, 2008. Disponível em: <http://www.gpo.gov/fdsys/pkg/CHRG-110hhrg42881/ pdf/CHRG-110hhrg42881.pdf> . Acesso em: 04 set. 2013.

VIEIRA, E. R.; ALBUQUERQUE-OLIVEIRA, P. R.; BARBOSA-BRANCO, A. Work disability benefits due to musculoskeletal disorders among Brazilian private sector workers. BMJ Open, London, v. 1, n. 1, p. e000003, 2011. http://dx.doi.org/10.1136/ bmjopen-2011-000003. PMid:22021719

WEBB, C. P. et al. Epidemiology of heavy alcohol use in Ukraine: findings from the world mental health survey. Alcohol and Alcoholism, Oxford, v. 40, n. 4, p. 327-335, 2005. http://dx.doi.org/10.1093/alcalc/ agh152. PMid:15824065

WÜNSCH FILHO, V. Reestruturação produtiva e acidentes de trabalho no Brasil: estrutura e tendências. Cadernos de Saúde Pública, Rio de Janeiro, v. 15, n. 1, p. 41-51, 1999. http:// dx.doi.org/10.1590/S0102-311X1999000100005. PMid:10203445 